\title{
NÂNG CAO HIỆU QUẢ GIÁO DỤC ĐẠO ĐỨC CHO SINH VIÊN ĐẠI HỌC Ở VIẸT NAM HIỆN NAY
}

\author{
PHẠM THI LAN \\ Khoa Lý luận chính trị, Trường Đại học Công nghiệp Thành phố Hồ Chí Minh \\ thulandhsp@gmail.com
}

Tóm tắt. Nước ta hiện nay đang trong giai đoạn chịu sự tác động mạnh mẽ của xu thế hội nhập quốc tế với nhiều biến động phức tạp của xã hội. Trước những biểu hiện suy thoái về đạo đức, lối sống của một bộ phận sinh viên thì việc giáo dục đạo đức cho sinh viên Việt Nam càng trở nên quan trọng và cần thiết. Trong bài viết này, tác giả tập trung luận giải những lý thuyết cơ sở của vấn đề đạo đức và giáo dục đạo đức; phân tích nguyên nhân ảnh hưởng và đề xuất một số giải pháp khắc phục vấn đề cho sinh viên đại học ở Việt Nam hiện nay.

Từ khóa. Đạo đức, giáo dục đạo đức, sinh viên đại học.

\section{IMPROVING THE EFFICIENCY OF ETHICAL EDUCATION FOR UNIVERSITY STUDENTS IN VIETNAM TODAY}

\begin{abstract}
In the current period, our country is uder the strong impact of the international intergration trendwith many complicated changes of society.Facing the expression of moral decline and the lifestyle of a part of the students. Therefore . the ethical education for Vietnamese students becomes even more important and necessary. In this article, the author focuses on interpreting the basic theories of ethics and ethical education; analyzing the causes of influence and proposing some solutions to overcome the problem of ethical education for university students in Vietnam today.
\end{abstract}

Keywords. Ethics, ethical education, university students.

\section{1. ĐẠT VẤN ĐỀ}

Đạo đức là một trong những vấn đề có ý nghĩa quyết định chiều hướng vận động và sự hưng thịnh của mỗi quốc gia. Dưới sự tác động của nền kinh tế thì vấn đề đạo đức lại trở nên quan trọng đối với mỗi con người sống trong xã hội Việt Nam hiện nay. Dưới sự tác động mạnh mẽ của cuộc cách mạng công nghiệp lần thứ 4 đang diễn ra trên tất cả các lĩnh vực của đời sống xã hội, giáo dục đạo đức cho sinh viên đại học ở Việt Nam hiện nay đã trở thành vấn đề được quan tâm của toàn ngành giáo dục và xã hội. Để không ngừng nâng cao chất lượng và hiệu quả của công tác giáo dục đạo đức cho sinh viên Việt Nam hiện nay, chúng ta phải phân tích rõ những nguyên nhân ảnh hưởng tới quá trình giáo dục đạo đức cho sinh viên trường đại học ở Việt Nam hiện nay là điều vô cùng cần thiết. Đây chính là một trong những nhiệm vụ thiết thực để đổi mới mạnh mẽ giáo dục, đào tạo theo hướng "coi trọng phát triển phẩm chất, năng lực của người học".

\section{NỘI DUNG}

\subsection{Những vấn đề chung về đạo đức và giáo dục đạo đức}

Đạo đức là một trong những vấn đề có ý nghĩa quyết định chiều hướng vận động và sự hưng thịnh của mỗi quốc gia. Dưới sự tác động của nền kinh tế thì vân đề đạo đức lại trở nên quan trọng đối với mổi con người sống trong xã hội Việt Nam hiện nay. Đạo đức là một vấn đề được các nhà tư tưởng và triết học đề cập đến từ lâu được xã hội mọi thời đại quan tâm và coi trọng. Với Khổng Tử đạo đức là gốc của con người, nói đến con người trước hết là nói đến đạo đức. Đúng như thiên "Học nhi" - Sách Luận ngữ đã viết: "Làm người có nết hiếu, đễ thì ít ai dám xúc phạm bề trên. Không thích xúc phạm bề trên mà thích làm loạn thì chưa từng có. Người quân tử chăm chú vào việc gốc, gốc mà vững thì đạo đức sinh ra. Hiếu, đễ là gốc của đức nhân...” [2]. Nhà tư tưởng lỗi lạc của Phương Tây Democritus đã đưa ra quan niệm về đạo đức gắn liền với hành vi của con người khi ông cho rằng "Niềm vui và sự bất mãn tạo thành ranh giới giữa những gì hữu ích và những gì có hại" [1].

Ở Việt Nam cũng có rất nhiều quan niệm khác nhau về đạo đức. Các tác giả nhìn nhận vấn đề đạo đức dựa trên nhiều góc độ, nhiều cách tiếp cận, có thế đưa ra một trong những quan niệm tương đối gần gũi, dễ hiểu và khái 
quát như: "Đạo đức là một hình thái ý thức xã hội đặc biệt, bao gồm một hệ thống nhũng quan điểm, quan niệm, nhũng quy tắc, nguyên tắc, chuẩn mực xã hội. Nó ra đời, tồn tại và biến đổi tù̀ nhu cầu xã hội trong mối quan hẹ giữa con người với con người, giữa cá nhân với xã họi ”' [5].

Có thể nói cùng với sự vận động và phát triển của xã hội, các quy tắc, chuẩn mực đạo đức này cũng biến đổi theo; với những cách hiểu có khác nhau nhưng chung quy lại đều có quan điểm thống nhất đó là chú trọng giáo dục đạo đức nhân văn, thực hiện công tác giáo dục bằng nhiều hình thức khác nhau; bởi vì việc giáo dục đạo đức cho sinh viên hiện nay là điều quan trọng và cần thiết.

Giáo dục đạo đức được hiểu là quá trình truyền tải, gắn kết và phát triển ở người học những kiến thức kỹ năng, thái độ, giá trị và những kỹ năng cần thiết trong cuộc sống. Đạo đức được lồng ghép vào sự định hướng phát triển các kỹ năng nhận thức, giải quyết vấn đề, sự hiểu biết, thái độ hành vi ứng xử đối với xã hội và các khía cạnh cảm xúc tác động đến tư duy đạo đức của người học. Do vậy, khoa học về đạo đức nghiên cứu một hệ thống các quy tắc ứng xử được trang bị cho người học để làm chuẩn cho hành vi ứng xử, để nhận thức và hành động, phân biệt được điều đúng, sai trong cuộc sống hàng ngày. Các nhà khoa học nghiên cứu về triết học giáo dục và giáo dục đạo đức đã chỉ ra mục đích của giáo dục đạo đức là giúp sinh viên trở thành những người biết tự chủ về hành vi, hành động đúng đắn, nhưng đồng thời cũng tạo ra sự gắn kết với các giá trị cơ bản như sự tôn trọng và trách nhiệm cá nhân đối với bản thân và đối với cộng đồng xã hội.

Nhìn chung có thể hiểu giáo dục đạo là một phần của quá trình giáo dục đào tạo con người để họ trở thành những người vừa có kiến thức hiểu biết về mọi lĩnh vực của đời sống vừa có cách ứng xử đúng đắn trong "tổng hòa các mối quan hệ xã hội" để giúp họ trở thành những người có tư duy đạo đức, có được sự hạnh phúc, trở thành những người có ích trong xã hội. Cách hiểu này cũng đã nhấn mạnh việc giáo dục đạo đức cho sinh viên đã và đang trở thành nhiệm vụ cấp bách, nhiệm vụ hàng đầu của gia đình, nhà trường và toàn xã hội.

\subsection{Những nhân tố tác động đến quá trình giáo dục đạo đức sinh viên hiện nay}

\subsubsection{Do sư phát triển của nền kinh tế}

Sự phát triển về kinh tế đã mở ra nhiều cơ hội về lợi nhuận nên họ tìm cách kìm hãm lẫn nhau, lợi dụng lấn nhau, kẻ lớn bắt nạt kẻ nhỏ, coi đồng tiền là quyền lực vạn năng, ít quan tâm đến đời sống tinh thần của con người, sẵn sàng vi phạm các quy định đạo đức, lừa đảo lẫn nhau... miễn là kiếm được nhiều tiền. Từ đó đã ảnh hưởng đến một bộ phận sinh viên với lối sống vị kỷ, thờ ơ không quan tâm trước lợi ích của cộng đồng và xã hội đã làm ảnh hưởng xấu đến giá trị đạo đức lối sống của sinh viên. Mặt khác, do sự bùng nổ công nghệ thông tin tạo nên sự đua đòi của sinh viên là mua sắm điện thoại di động thông minh, từ đó các em vào internet, lên mạng xã hội, chơi game,vào những trang web đen, ... hình ảnh hoặc những bộ phim gây tác động không tốt đối với sự phát triển về nhân cách của sinh viên và đã làm cho các giá trị đạo đức truyền thổng dân tộc ngày càng bị mai một, làm hư hỏng các em bởi bản tính tò mò, hiếu động của tuổi mới lớn. Vấn đề này hiện nay đã diễn ra ở khắp vùng, miền, mọi thành phần xã hội khác nhau.

Vì một số ảnh hưởng nêu trên, đã có một bộ phận nhỏ sinh viên chưa có cách ứng xử phù hợp trong giao tiếp và hành động của bản thân đối với thầy cô giáo. Và thể hiện thái độ thiếu tôn trọng thầy cô khi không vừa ý mình, hoặc bực bội điều gì đó mà chưa nhận ra lỗi lầm của sinh viên họ mang theo những bực bội đó đăng lên trang mạng xã hội và cùng nhau bình luận về thầy cô đó, điều này đã làm ảnh hưởng trực tiếp đến nhân cách và suy thoái đạo đức nghiêm trọng của một số sinh viên như hiện nay. Mặt khác, việc nghỉ học, gian lận trong thi cử trở nên phổ biến hơn, bởi lẽ hiện nay sinh viên đã chuyển sang học theo hình thức tín chỉ và hình thức học này sinh viên được phép nghỉ học một số buổi học nhất định phụ thuộc vào số lượng tín chỉ của môn học cần tích lũy.

\subsubsection{Sự phối hợp gia đình, nhà trường và xã hội chưa thật sự đồng đều}

\section{- Về phía gia đình:}

Do gia đình dạy dỗ, chăm sóc yêu thương con cái chưa thật sự đúng cách. Thời gian chủ yếu là các em sống với gia đình và giao tiếp ngoài xã hội, gia đình chính là mai trường đầu tiên của mỗi người và bố mẹ là người thầy đầu tiên và suốt đời của các em. Vì vậy, mọi thái độ và hành vi, cử chỉ của cha mẹ đều tác động mạnh mẽ, sâu sắc đến sự hình thành nhân cách của sinh viển.

Thực tế thì có gia đình cha mẹ không gương mẫu, cha mẹ ly hôn, thiếu quan tâm. Buông lỏng việc giáo dục con; cũng không ít gia đình chỉ lo quan tâm đến công việc kiếm tiền, lo cuộc sông mưu sinh ít có thời gian quan tâm đến con cái. Khi con đến trường học và rồi lúc về nhà cha mẹ cũng chẳng quan tâm đến con cần học những gì, phải làm những gì cho con cái, chưa tạo được điều kiện cho con học tập ở nhà một cách tốt nhất. Việc liên lạc với giáo viên chủ nhiệm và giáo viên bộ môn còn ít và hạn chế. Cưng từ đó, việc giáo dục đạo 
đức con em còn nhiều hạn chế, thậm chí là không hiệu quả.

Với sinh viên khi bước vào giảng đường đại học, các em đều đến từ những vùng quê, thành phố khác nhau nên khoảng cách giàu nghèo gây ra sự bất bình đẳng trong xã hội. Hiện tượng "kẻ ăn không người lần không ra". Nhiều cô, cậu nhà giàu có điều kiện suốt ngày lêu lỏng, tiêu xài tiền không biết tiếc. Ngược lại, không ít sinh viên con nhà nghèo sống lay lắt trong những căn nhà trọ tạm bợ, vừa đi học lại vừa cặm cụi đi làm thêm để giúp đỡ gia đình trong việc chi tiêu cuộc sống. Sinh viên hầu hết là sống xa gia đình, thiếu thốn tình cảm của cha mẹ nên hiện tượng sống thử đã trở thành trào lưu ở một số nơi. Mặc dù sinh viên hiểu lối sống thử này hoàn toàn không phù hợp với văn hóa sống và đi ngược lại với những giá trị tốt đẹp của dân tộc. Lối sống này biểu hiện sự xuống cấp nghiêm trọng về mặt đạo đức trong mộsố bộ phận sinh viên.

- Về phía nhà trường

Cùng với sự phát triển của xã hội Việt Nam như hiện nay thì những vấn đề đang lo ngại đó là đạo đức học đường của một bộ phận sinh viên đang xuống cấp, dẫn đến những vụ án nghiêm trọng, những hành vi gian lận ở nhiều góc độ khác nhau... Đó là những biểu hiện lệch lạc trong hành vi, nhân cách đạo đức sinh viên. Sự xuống cấp của đạo đức có rất nhiều nguyên nhân song một phần trách nhiệm cũng thuộc về nhà trường - nôi của giáo dục hình thành những phẩm chất đạo đức.

Do chương trình, nội dung giảng dạy của nhà trường, có những việc tưởng như là nhỏ nhưng lại tác động đến cả quá trình hình thành nhân cách của sinh viên; nhiều khi nhà trường ít quan tâm đến việc giáo dục đạo đức, nhân cách của sinh viên. Việc dạy đạo đức trong nhà trường vẫn được coi là nhiệm vụ cần thiết và quan trọng để giảm bớt sự xuống cấp về̀ mặt đạo đức. Tuy nhiên, việc giáo dục đạo đức hầu như mang nặng tính lý thuyết không gắn liền với đời sống, thiếu kỹ năng sống. Chương trình học với những kiến thức mang nặng tính triết học, hàn lâm, khô cứng và chưa mang đậm tính thực tiễn.

Một số giảng viên lại cho rằng việc dạy và học giáo dục đạo đức chỉ thông qua các môn lý luận chính trị. Chúng ta biết rằng kiến thức trong mỗi một môn học nào cũng có tính giáo dục cả, vậy mà người dạy không biết lồng ghép để định hướng tư tưởng cho sinh viên. Người dạy vẫn coi trọng nặng về dạy chữ nhưng lại nhẹ về dạy người, chỉ biết truyền thụ về kiến thức chuyên môn, không quan tâm đến uốn nắn chỉnh sữa những hành vi sai trái của sinh viên. Vì vậy, đã đến lúc phải thay những bài dạy về đạo đức xa vời, các trường cần giáo dục cho sinh viên về lối sống nhân ái, bao dung, độ lượng về cách ứng xử các chuẩn mực đạo đức trong các mối quan hệ xã hội.

- Về phía xã hội

Việc học tập, tu dưỡng rèn luyện đạo đức cho sinh viên là một việc làm cần thiết và nhận được sự quan tâm của xã hội. Sinh viên cần xác định được nhiệm vụ trọng tâm là học tập và tu dưỡng rèn luyện đạo đức. Cần tổ chức cho sinh viên tham gia các hoạt động tình nguyện như tình nguyện mùa hè xanh, hiến máu nhân đạo, phong trào đền ơn đáp nghĩa... qua đó để sinh viên thường xuyên, tích cực trau dồi nhân cách, bồi đắp những giá trị đạo đức, sống chân thành, trung thực, yêu thương giúp đỡ mọi người trong xã hội, để hình thành ở mỗi sinh viên có lòng nhân ái bao dung, hành vi ứng xử mang tính văn hóa. Trách nhiệm của xã hội là phải quan tâm đầy đủ đến việc giáo dục đạo đức, tiếp thu và hoàn thiện những chuẩn mực đạo đức mới góp phần khắc phục sự suy thoái về đạo đức trong xã hội hiện nay.

Với những tác động không tốt về những tư tưởng văn hóa xấu, ngoại lại và mặt trái của kinh tế thị trường... đã biểu hiện sự suy thoái về đạo đức, mờ nhạt lý tưởng, mang theo lối sống thực dụng. Các tệ nạn xã hội đã xâm nhập và ảnh hưởng trực tiếp trong trường học, một số sinh viên bị sa vào tệ nạn xã hội thậm chí gây án như giết người cướp của... tuy nhiên số này không phổ biến nhưng lại có xu hướng gia tăng, làm suy thoái nhân cách đạo đức, gây ra nỗi đau cho người thân của mình, đã ảnh hưởng không nhỏ trực tiếp đến công tác giáo dục đạo đức sinh viên, đến an ninh trật tự trong xã hội.

\subsection{Một số giải pháp nâng cao hiệu quả giáo dục đạo đức cho sinh viên đại học ở Việt Nam hiện nay 2.3.1. Tăng cuờng việc giáo dục tư tưởng chính trị và pháp luật cho sinh viển đại học ở Việt Nam}

Tiếp tục giáo dục cho sinh viên thấy được bản chất cách mạng, khoa học của chủ nghĩa Mác - Lênin và tư tưởng Hồ Chí Minh, trang bị cho sinh viên thế giới quan và phương pháp luận khoa học đúng đắn; giúp sinh viên nhận thức đúng đắn về tự nhiên, xã hội và tư duy để tạo niềm tin khoa học trong hành động của sinh viên. Từ đó, giáo dục cho sinh viên hiểu rõ và có nhận thức cũng như hành động đúng đắn về các chủ trương, đường lối, quan điểm của Đảng, chính sách pháp luật của Nhà nước. Bản thân mỗi sinh viên sẽ tự ý thức được hành động của mình để trở thành một người công dân tốt, có ích cho xã hội. Luôn sống, học tập và làm việc theo Hiến pháp và Pháp luật. Hình thành ở sinh viên lòng yêu quê hương đất nước, nhận thức đúng đắn về con đường tiến lên xây dựng chủ nghĩa xã hội là một tất yếu của lịch sử. Để sinh viên thấy được thái độ và trách 
nhiệm của mình trước vận mệnh của đất nước, dân tộc Việt Nam mà Hồ Chí Minh là tấm gương sáng về đạo đức cho thế hệ sinh viên Việt Nam tiếp tục học tập, rèn luyện và phấn đấu.

Giáo dục pháp luật đóng vai trò quan trọng trong việc giáo dục các giá trị đạo đức tạo ra môi trường pháp lý để bảo vệ những phong tục tập quán, truyền thống tốt đẹp của dân tộc. Giáo dục pháp luật giúp sinh viên định hướng hành vi con người trong xây dựng lối sống cho sinh viên. Trên thực tế, sinh viên chủ yếu sống ở nông thôn, quen lối sống lệ làng, tục lệ, lề lối truyền thống lâu đời nên sự hiểu biết về pháp luật của sinh viên còn bị hạn chế, thậm chí là coi thường pháp luật: "phép vua thua lệ làng", "vua thua thằng liều", tình trạng thiếu hiểu biết về pháp luật tự xã hội. Đảng Cộng sản cũng đã khẳng định và chỉ rõ: "Môi trường văn hóa bị xâm hại, lai căng, thiếu lành mạnh, trái với thuần phong mỹ tục, các tệ nạn xã hội, tội phạm và sự xâm nhập của các sản phẩm và dịch vụ độc hại làm suy đồi đạo đức, nhất là thanh thiếu niên rất đáng lo ngại” [4]. Vì vậy, phải giáo dục pháp luật cho sinh viên hiểu rõ để không vướng vào những văn hóa thiếu lành mạnh. Giáo dục đạo đức nhưng phải đi liền với pháp luật. Đạo đức và pháp luật có mối quan hệ chặt chẽ với nhau, tác động cùng thúc đẩy nhau phát triển.

Việc hoàn thiện thể chế và thực thi pháp luật sẽ đẩy lùi được những hiện tượng tiêu cực trong xã hội, thúc đẩy các mối quan hệ giáo dục pháp luật sâu rộng đến sinh viên. Ở môi trường học đường, ít nhiều cũng đã chịu sự tác động mặt trái của nền kinh tế thị trường đã làm tha hóa một bộ phận sinh viên với biểu hiện như lười học, ý thức học tập kém, tiếp thu thụ động, gian dối trong học tập và thi cử đang ngày trở nên phổ biến hơn. Hiện nay công tác giáo dục pháp luật cho sinh viên con nhiều hạn chế, do vậy tình trạng vi phạm đạo đức trong sinh viên có chiều hướng gia tăng. Một số sinh viên không coi trọng môn học pháp luật, môn chính trị trong trường đại học, sinh viên luôn có ý nghĩ đó là môn học phụ, học để cho qua... từ đấy dẫn đến vi phạm pháp luật một cách đáng tiếc. Cần có quy chế quản lý nghiêm khắc đối với sinh viên theo pháp luật của nhà nước và theo nội quy của nhà trường. Tuy nhiên cần có những chính sách quan tâm đến những sinh viên nghèo vượt khó, sinh viên vùng sâu, vùng $\mathrm{xa}$, biển đảo... để giúp các em có hứng thú trong học tập, hiểu được những điều mình nên làm và không nên làm. Từ đó, giúp các em tự định hướng và điều chỉnh được hành vi của bản thân mình.

Để làm được điều đó thì rất cần sự quan tâm của Đảng và Nhà nước như việc xây dựng và hoàn thiện rõ hơn nữa các quy định về pháp luật, văn hóa, đạo đức và góp phần tôn tạo, giữ gìn những giá trị truyền thống đạo đức của dân tộc. Cần có chính sách quan tâm và đẩy mạnh hơn nữa trong xây dựng môi trường học tập lành mạnh, học hỏi kinh nghiệm thế giới để từng bước hoàn thiện hệ thống pháp luật, mở ra nhiều cơ hội cho sinh viên tích cực học tập, xây dựng lối sống mới. Qua đó, giúp sinh viên ý thức đầy đủ hơn về trách nhiệm của mình đối với đất nước, với gia đình, nhà trường và xã hội.

\subsubsection{Kết hợp chặt chẽ giữa gia đình, nhà truò̀ng và xã hội trong việc giáo dục đạo đức về xây dụng lối sống mới cho sinh viên đại học ở Việt Nam hiện nay}

Như chúng ta đã biết, gia đình luôn được coi là tế bào của xã hội, là cầu nối giữa cá nhân với xã hội, nơi ươm mầm và nuôi dưỡng nên những phẩm chất nhân cách trong mồi con người của xã hội. "Môi trường gia đình tạo ra nguồn gốc nhân cách của đứa trẻ, nếu môi trường đó không ổn định, nhiễu loạn sẽ ảnh hưởng nhiều đến sự hình thành nhân cách trẻ" [8]. Bởi gia đình là nơi cuộc sống bắt đầu và tình yêu không bao giờ kết thúc. Là điểm tựa vững chắc nhất, là bến đỗ bình yên nhất đối với mỗi con người. Gia đình có thể giúp con người vượt qua mọi khó khăn trong cuộc sống, là nơi tạo ra những niềm tin và sự hy vọng để vượt qua những vất vả, khó khăn trong cuộc sống. Xã hội càng phát triển thì có rất nhiều mối quan hệ khác nhau, nhưng không có mối quan hệ nào bằng tình cảm gia đình bởi lẽ gia đình giúp con người gắn kết với nhau, giúp xã hội phát triển càng phát triển hơn. Từ đó giúp sinh viên hiểu được gia đình chính là nơi nuôi dưỡng con người của những người thân yêu ruột thịt của chúng ta; nơi đó là một mái ấm có cả cha mẹ, ông bà và cả anh chị em. Từ đó, tạo thêm cho sinh viên những nghị lực có thể tự tin hơn khi bước vào cuộc sống đầy gian nan và thử thách sẽ vững bước vượt qua để hoàn thành tốt nhiều biến động thử thách lớn lao hơn nữa.

Đảng Cộng sản Việt Nam đã chỉ rõ "Chăm lo giáo dục, đào tạo rèn luyện thế hệ trẻ là trách nhiệm của Đảng, Nhà nước, các tổ chức trong hệ thống chính trị, của gia đình, nhà trường và của toàn xã hội” [3]. Văn kiện đại hội Đảng lần thứ XI khẳng định: "Kểt hợp và phát huy đầy đủ vai trò của xã hội, gia đình và nhà trường, từng tập thể lao động, các đoàn thể và cộng đồng dân cư trong việc chăm lo xây dựng con người Việt Nam giàu lòng yêu nước, có ý thức làm chủ, trách nhiệm công dân, có tri thức, sức khỏe, lao động giỏi, sống có văn hóa, nghĩa, có tinh thần quốc chân chính" [4]. Lúc sinh thời, Hồ Chí Minh đã từng dạy: "Không có việc gì khó, chỉ sợ lòng không bền, đào núi và lấp biển, quyết chí ắt làm nên" [6] giúp thanh niên biết yêu quê hương, đất nước; yêu Tổ quốc, yêu nhân dân và yêu chủ nghĩa xã hội... Bởi lẽ đó sẽ tạo nên động lực tinh thần vững chắc, khơi dậy lòng tự hào dân tộc, tự tôn dân tộc cùng với ý chí quyết tâm khồng chịu khuất phục, kiên cường 
với tình yêu Tổ quốc... Từ đó hình thành cho sinh viên ý thức tự mình vươn lên để làm chủ cuộc sống góp phần xây dựng và giữ gìn lối sống tốt đẹp của con người Việt Nam trong thời đại mới.

Giáo dục đạo đức cho sinh viên là một việc làm cần thiết và quan trọng. Theo Hồ Chí Minh, đạo đức không phải từ trên trời sa xuống mà nó là kết quả trực tiếp của hoạt động giáo dục và sự rèn luyện của mỗi bản than con người. Hồ Chí Minh khẳng định: "Giáo dục các em là việc chung của gia đình, trường học và xã hội. Bố mẹ, thầy giáo và người lớn phải cùng nhau phụ trách" [7]. Với xu thế hội nhập quốc tế như hiện nay đã mở ra cho sinh viên những cơ hội và thách thức lớn mà một trong những thách thức lớn đó là sự tác động về mặt đạo đức. Với kinh nghiệm sống còn non trẻ, cùng với đó là sự bồng bột thì sinh viên dễ bị cán dỗ trước các giá trị về vật chất, dễ bị cuốn vào vòng xoáy của đồng tiền mà có khi quên đi giá trị làm người, tự đánh mất lương tâm và danh dự của chính mình... Để điều chỉnh tốt các mối quan hệ trong xã hội sinh viên phải tự ý thức được những gì mình đang làm và hiểu tiền cũng quan trọng nhưng không phải là tất cả, mà có những thứ quan trọng hơn đó chính là nhân phẩm của một con người.

Để làm tốt được điều này cần có sự thống nhất giữa gia đình, nhà trường và xã hội cần xây dựng đời sống văn hóa, nếp sống mới cho các tầng lớp nhân dân, trong đó có sinh viên. Phải bắt đầu xây dựng lối sống mới từ gia đình, đến trường học tạo ra không gian văn hóa lành mạnh để sinh viên đều được sống, học tập lao động và hưởng thụ. Bên cạnh đó, gia đình, nhà trường và xã hội phải thường xuyên trao đổi, phối hợp với nhau để bồi đắp cho sinh viên những giá trị đạo đức là cơ sở định hướng trong xây dựng lối sống mới cho sinh viên. Sự phối hợp chặt chẽ ba môi trường giáo dục trên là sự đảm bảo thống nhất trong nhận thức cũng như trong hoạt động giáo dục cùng một mục tiêu, mục đích, cùng một hướng để thúc đẩy quá trình nhận thức của sinh viên. Nếu tách rời sẽ dẫn đến sự dao động, hoang mang trong việc tiếp nhận các giá trị tốt đẹp về phẩm chất nhân cách để sinh viên trở thành những công dân có ích cho đất nước.

\subsection{3 . Phát huy ý thức tụ giác, tụ giáo dục của sinh viên đại học ở Việt Nam hiện nay theo tư tưởng đạo đức Hồ Chí Minh}

Hồ Chí Minh của chúng ta đã từng nói: “Có tài mà không có đức là người vô dụng, có đức mà không có tài thì làm việc gì cũng khó”. Tài và Đức là phẩm chất thống nhất của mỗi con người. Nếu đạo đức là tiêu chuẩn cho mục đích hành động thì tài là phương tiện để thực hiện mục đích đó. Vì vậy, tài và đức luôn đi song hành cùng nhau. Nguyên tắc cơ bản trong tư tưởng Hồ Chí Minh về đạo đức là nói đi đôi với việc làm; lý luận và thực tiễn phải thống nhất với nhau là cơ sở nền tảng đánh giá đạo đức của con người. Từ sự đúc kết của thực tiễn việc nâng cao chất lượng công tác giáo dục đạo đức Hồ Chí Minh cho sinh viên đại học là cần thiết để phát huy tính tự giác, tự giáo dục của sinh viên gắn với việc thực hiện nhiệm vụ và học tập.

Thứ nhất, sinh viên phải xác định được mục tiêu học tập đúng đắn. Bản thân họ là người có quyết định đến quá trình học tập của mình, vì vậy sinh viên phải xây dưng cho mình một động cơ học tập đúng đắn; học để mở rộng sự hiểu biết, học để làm việc, học để hoàn thiện bản thân để góp phần thúc đẩy cải tạo và phát triển xã hội. Nếu sinh viên xác định đúng động cơ học tập sẽ tạo nên được thái độ tích cực trong học tập ở sinh viên.

Thứ hai, sinh viên cần chủ động xây dựng kế hoạch học tập và quyết tâm thực hiện kế hoạch đó một cách nghiêm túc. Muốn thực hiện tốt thì sinh viên phải phân ra được từng kế hoạch khác nhau như ngắn, trung và dài để có sự điều chỉnh phù hợp trong quá trình học tập. Tuy nhiên, kế hoạch học tập đề ra thực tế phải dựa trên khả năng và năng lực của bản thân họ.

Thứ $b a$, sinh viên cần xây dựng được phương pháp tự học hiệu quả. Tự ý thức trong việc tự học giữ một vai trò vô cùng quan trọng trong việc lĩnh hội tri thức và hình thành nên phẩm chất đạo đức cá nhân ở sinh viên. Bản thân sinh viên phải tự rèn luyện cho mình kỹ năng tự học để có được kết quả cao. Để đạt hiệu quả trong phương pháp tự học sinh viên phải bắt đầu tự đọc sách ở nhà, đọc giáo trình trước khi đến lớp, tự tìm hiểu bài học mới... Việc phát huy phương pháp học tập sẽ tạo ra thái độ đúng đắn với việc học tập của mình cùng giúp đỡ bạn bè học tốt, tạo và thành lập học nhóm để bổ sung kiến thức lẫn nhau, giúp đỡ lấn nhau cùng phải phát triển trên con đường học tập của sinh viên.

Thứ tư, thực hiện tốt nội quy, quy chế của nhà trường, đi học đầy đủ, đúng giờ, nghiêm túc trong học tập, thi cử, luôn có thái độ tôn trọng thầy cô giáo, người trên tuổi. Mỗi sinh viên đều đển từ những vùng quê khác nhau, việc hỗ trợ, quan tâm chia sẻ, giúp đỡ lẫn nhau để vươn lên học tập, rèn luyện tốt, học hỏi lẫn nhau để bản thân mỗi sinh viên tự hoàn thiện chính mình; tham gia các hoạt động phong trào do nhà trường tổ chức. Với các hoạt động thể thao, văn hóa văn nghệ, phong trào đền ơn đáp nghĩa, những hoạt động tình nguyện mùa hè xanh, hiến máu nhân đạo... Thông qua những hoạt động này sinh viên có điều kiện học hỏi và hoàn thiện phẩm chất đạo đức cá nhân sinh viên. 


\section{KẾT LUẬN}

Đảng Cộng sản Việt Nam chỉ rõ: "Coi trọng bồi dưỡng cho học sinh, sinh viên khát vọng mãnh liệt xây dựng đất nước giàu mạnh, gắn liền với lập nghiệp bản thân với tương lai của cộng đồng, của dân tộc, trau dồi học sinh, sinh viên bản lĩnh, phẩm chất và lối sống của thế hệ trẻ Việt Nam hiện đại” [9]. Giáo dục đạo đức trong sinh viên hiện nay có ý nghĩa rất quan trọng, bởi sinh viên là những người có tri thức sẽ là lực lượng kế thừa và phát huy những thành quả cách mạng của Đảng và dân tộc tiêu biểu cho trí tuệ Việt Nam. Muốn làm tốt được điều đó cần phải phối hợp, liên kết của cả 3 lực lượng: Gia đình, nhà trường và xã hội... Sự kết hợp đó giữ một vai trò vô cùng quan trọng đối với việc giáo dục đạo đức cho sinh viên hiện nay, bởi lẽ sự thay đổi chóng mặt về kinh tế, khoa học, kỹ thuật và công nghệ đã tác động mạnh mẽ tới hành vi đạo đức của sinh viên, từ đó chúng ta phải tìm ra những biện pháp giáo dục đạo đức cho sinh viên một cách phù hợp nhất để các em bồi dưỡng thêm phẩm chất đạo đức của bản thân mình.

\section{TÀI LIỆU THAM KHẢO}

1. A.Guseinov (2016), "The Ethic of Democritus", Published online: 20 Dec 2014, in https://www.tandfonline.com/doi/abs/10.2753/RSP1061-1967260153

2. Doãn chính (1997), Đại cuơng triết học Trung Quốc, Nxb Chính trị Quốc gia, Hà Nội.

3. Đảng cộng sản Việt Nam (1996), Văn kiện đại hội Đảng lần thứ VII, Nxb Chính trị Quốc gia, Hà Nội

4. Đảng cộng sản Việt Nam (2011), Văn kiện đại hội Đảng lần thứ XI, Nxb Chính trị Quốc gia, Hà Nội

5. Trần Hậu Khiêm (1996), Giáo trình Đạo đức học, Nxb Chính trị Quốc gia, Hà Nội.

6. Hồ Chí Minh (2011), Toàn tập, tập 9, Nxb Chính trị Quốc gia, Hà Nội

7. Hồ Chí Minh (2011), Toàn tập, tập 11, Nxb Chính trị Quốc gia, Hà Nội

8. Lê Thi (1997) Vai trò gia đình trong việc xây dựng nhân cách con nguời. Nhà xuất bản Phu nũ.

9. Trần Sỹ Phán “Sinh viên với định hướng giá trị nhân cách”, Tạp chí Lý luận chính trị, 1996

Ngày nhận bài: 19/03/2020

Ngày chấp nhận đăng: 29/07/2020 